\title{
A MULTI-TIERED APPROACH TO SILT'I VERB MORPHOLOGY
}

\author{
Ernst-August Gutt \\ Addis Ababa, Ethiopa
}

\begin{abstract}
The replacement of the familiar linear phonological representations of the SPE-type by the multi-tiered configurations proposed in autosegmental phonology has enriched the theoretical apparatus available to the linguist and has opened the way for a better understanding of the workings of phonology. One particular strength of this theory is that it predicts the existence of distinct subsystems within a phonological system and offers a principled account of their interactions. Applied to the aspectual inflection of Silt' $i$ verbs, the multi-tiered approach proves its potential by accommodating two distinct subsystems of inflection, viz. CV-pattern inflection and ablaut inflection, in a unified, principled description. From a more general point of view, this paper sketches one possible way of integrating syllable theory as a distinct subsystem into an autosegmental system of phonology.
\end{abstract}

\section{Introduction}

This paper ${ }^{l}$ attempts to pursue both a language specific, descriptive goal and a (more) universal, theoretical goal. On the descriptive side, the aim is to give an account of the aspectual inflection of the Silt' $i^{2}$ verb root in its

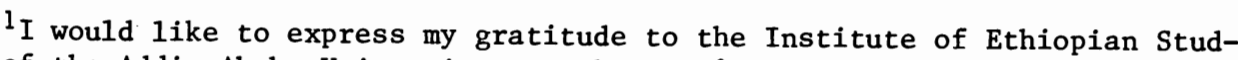
ies of the Addis Ababa University; to the Silt'i people, especially to Ato Hussein Redi, who helped me learn and analyse their language; to my colleague $\mathrm{Dr}$. Klaus Wedekind of the Summer Institute of Linguistics for his encouragement during my fieldwork; to $\mathrm{Dr}$. Richard Hayward of the School of Oriental and African Studies, Dr. Richard Hudson, and Dr. John Wells of University College London for their comments on an earlier draft of this article; and in particular, I want to thank Professor Neil Smith (UCL) for his advice and encouragement in the writing of this paper, which is a revised version of my M.A. dissertation (UCL).

${ }^{2}$ The Silt'i language is spoken by a group of ca. 150,000 people in the southwestern part of the Shewa Administrative Region of Ethiopia. It is generally classified as belonging to the "Eastern Gurage" group in the Ethio-Sem- 
underived forms, and on the theoretical side, this study is meant to be a further step in the recent developments exploring the new possibilities (and their limits?) opened up by the "autosegmental" or multi-tiered approach to phonology and morphology.

The paper is organised into five major parts. Part 1, the Introduction, is followed by an outline of the theoretical framework employed (Part 2). Part 3 presents the phonological structure and aspectual inflection of the simple Silt' $i$ verb stem in an informal way. Part 4 aims at describing these aspects of the Silt' $i$ verb in terms of a multi-tiered approach, and Part 5 evaluates the findings of this paper. The Appendix gives a brief sketch of the phonology of Silt'i insofar as it is relevant to this study.

2. The Theoretical Framework

The framework assumed here is that of a multi-tiered approach, as developed first of all under the name of "autosegmental phonology" (cf. for example, Goldsmith [1979]) for a variety of phonological phenomena, and later on extended in various directions, such as morphology by McCarthy [1982a, 1981] and sy1lable theory by Clements and Keyser [1981]. McCarthy chose to call his approach a "prosodic theory of nonconcatenative morphology". For the purposes of this study, however, I want to suggest the label "multi-tiered" since this term seems to capture one of the most significant aspects of both autosegmental phonology and of McCarthy's prosodic approach to morphology. In both approaches, the essentially linear strings of conventional generative phonology are "sliced up" horizontally into a number of (parallel) layers of features, called "tiers"; the tiers stand in associative relationships to each other, which are subject to a number of conditions and conventions that determine the

itic language family. The data on which this paper is based represent the dialect spoken in the northern part of the Silt'i region, where I was working from 1976 to 1980 carrying out linguistic research in association with the Institute of Ethiopian Studies of the Addis Ababa University. Information about the Silt'i language is contained in Drewes [1960], Leslau [1961], and Hetzron [1972]. Leslau [1979] includes a dictionary of Silt'i (vol. 1, pp. 961-1032) and some information about Silt'i phonology. in vol. 3. Gutt [1983] gives a phonemic description of Silt'i phonology. 
we11-formedness or otherwise of a given expression. One of the most important properties of a tier is that it constitutes a domain of its own in certain respects of well-formedness. The following hypothetical example may serve to illustrate some of the points made so far: the word dédòdldá might have the following three-tiered representation:

(1) tonal tier syllable tier segmental tier

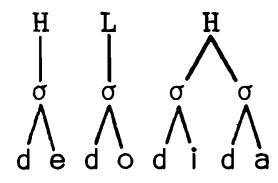

In this example, each tier has its own "vocabulary": the tonal tier admits only the two elements $\mathrm{H}$ and $\mathrm{L}$, representing high and low tone respective$1 y$, whereas the syllable tier is constituted only of a string of $\sigma$ representing syllable nodes (cf. Clements and Keyser [1981]), and the segmental tier has as its vocabulary here the "ordinary" segments of the language in question. A tier may also have its own "syntactic" constraints. For example, one universal constraint that has been proposed is that on the tonal tier adjacent elements must not be identical, a constraint sometimes referred to as Leben's "Obligatory Contour Principle". (For a critical discussion of this, see Goldsmith [1979:36 and 163ff.].) A language-specific constraint could for example state that the number of syllable nodes may not exceed a certain number. Thus well-formedness conditions with either universal or language-specific scope may have to be expressed independently for each tier. The example given in (1) can also serve to illustrate the type of well-formedness conditions that may hold for the associative relationships between the various tiers: every syllabic element must ultimately be associated with at least one tonal element and at least one segmental element. This constraint would rule out expressions such as are represented in (2) below.
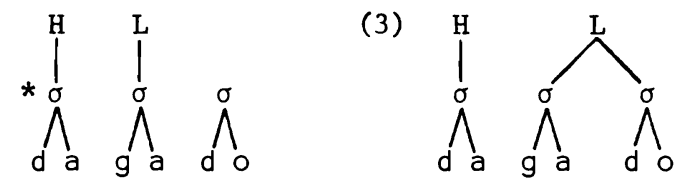

Supplemented by appropriate association conventions, e.g. those suggested 
by Clements \& Ford [1979], the ill-formed representation (2) could be transformed into the we11-formed expression (3). Another basic constraint on possible associations is that "Association lines do not cross" [Goldsmith 1979:27], ruling out a representation like that in (4), which could otherwise have been taken as a wel1-formed derivation from (2).

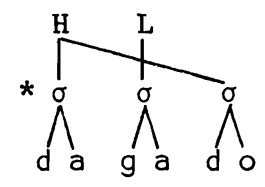

In contrast to phonological theories of the SPE-type, this multi-tiered theory abandons the concept of the segment as the sole carrier of all phonological information. A phonetic representation is no longer "...thought of formally as a two-dimensional matrix in which the columns stand for consecutive units and the rows stand for individual phonetic features" [Chomsky and Halle 1968:297], but rather as "composed of a set of several simultaneous sequences" of "atomic units" (or "autosegments") which are "cross-classified by distinctive features" [Goldsmith 1979:16]. These autosegments remain distinct at all stages of phonological processing, and may enter into many-to-many relationships with autosegments on other levels or "tiers". "In general ... there is a many-to-many association between autosegmental levels" [McCarthy 1982b: 128]. From a conceptual point of view, such a development seems promising in that it opens up the way for treating some of the complexities of phonological representations in terms of the interaction of a number of independent "subsystems" (tiers), each of which will hopefully be constrained by a small number of fairly simple conditions, a general trend of development that certainly has helped to advance the theory of syntax in great measure already.

\section{The Structure and Aspectual Inflection of Silt'i Verbs}

The tense-aspect inflection of the Silt' $i$ verb can be described in terms of three principal parts or stems from which all other tenses or aspects can be formed. The perfective stem enters into the formation of the simple past, present perfect, and past perfect tenses; the imperfective stem provides the basis for the present-future and for the past-imperfective tense, and the non- 
aspectual stem figures in the formation of the imperative and infinitive forms, as illustrated in (5) below. ${ }^{3}$
(5) Perfective stem:
k'atal
'ki11'
k'atal-a
'he killed'
Present Perfect
k'atal-a:n
'he has killed'
Past Perfect
k'atal-a:n na:ra
'he had killed'
Imperfective stem:
k'at I
Present-future
? i-k'at I-a:n
'he (will) kil1(s)'
Past Imperfective
?i-k'at I na:ra
'he used to kill'
Non-aspectual stem
$k^{\prime}(i) t^{4}$
Imperative
k'ital
'ki11! (imp. 2 sg. m)'
yi-k'tal
'let him kill! (imp. $3 \mathrm{sg} \mathrm{m}$ )'
Infinitive
k'ital-o:t
'to kil1'

In terms of its internal structure, the Silt'i verb stem can be viewed as consisting of a consonantal skeleton, made up of two to four consonants, and a set of one or more vowels which combine with the consonant skeleton to make up the fully specified verb stem, a system typical of the Semitic languages in general. The consonantal skeleton bears the basic lexical meaning of the word, whereas the vowel pattern is modified to mark derivation and inflection. Thus, in (5) the consonant skeleton would be $k^{\prime} t 1$, representing the meaning ' $k 111$ ', and the vowel patterns $a \mathrm{a}, \mathrm{a} \emptyset$, and $\emptyset$ a would represent the syntactic features "perfective", "imperfective", and "non-aspectual" respectively.

${ }^{3}$ Since 1ittle investigation has been done into the syntactic and semantic properties of the various inflectional forms, not too much importance should be attached to the labels chosen here. On an intuitive level, forms incorporating the perfective stem seem to refer to completed events, forms with the imperfective stem to incomplete or iterative events, and those with the third form of the stem seem to be unspecified in these respects, so that the label "non-aspectual" seems to be appropriate here.

${ }^{4}$ The / $\mathrm{i} /$ in parentheses is predictable from surface phonotactic constraints which trigger $i$-epenthesis to break up nonpermissible clusters, here a CC- sequence in word-initial position. 
But, as has been noted for other Ethio-Semitic languages before, "consonants alone seem not to be sufficient [as carriers of lexical meaning EAG] since some roots are differentiated also by vowels ..." [Bender and Hailu 1978: 10]. While this quote refers to Amharic, another member of the Ethio-Semitic family, in Silt'i, too, a number of verbs are differentiated by their vowels alone, e.g. fare 'fear' vs. fe:re 'invite to a wedding', k'at'a 'punish' vs. k'a:t'a 'measure', and kare 'dig vs. kore 'be proud'. Thus for certain groups of Silt'i verbs vocalic specifications need to be given in the underlying lexical representations not only to differentiate the verb roots from each other, but also to account for the fact that another system of aspectual inflection, different in kind from the one sketched above, is operative. This second inflectional system is illustrated in (6).

$\begin{array}{lllll}\text { a. herfective } & & \text { Imperfective } & & \text { Non-aspectual } \\ & \text { he:d } & \text { hi:d } & \text { 'go' } \\ \text { b. nozy } & \text { nozy } & \text { nuzy } & \text { 'become angry' } \\ \text { c. go:ra } & \text { go:ra } & \text { gu:ra } & \text { 'slaughter' } \\ \text { d. Je:lad } & \text { Je:ld } & \text { Ji:ld } & \text { 'shave' } \\ \text { e. t'o:k'as } & \text { t'o:k's } & \text { t'u:k's } & \text { 'beg' }\end{array}$

(Note: The raised letter $y$ indicates palatalisation.)

As can be seen, this system uses vowel raising to establish an ablaut-type inflection for the non-aspectual stems which are otherwise identical with the imperfective stems in terms of their vowel patterns. The data in (6) also illustrate that properties of the consonantal skeleton can have an effect on the inflectional patterns. Whereas verbs like fe:lad 'shave' and t'o:k'as 'beg', which have three stem consonants, differ in their perfective and imperfective stems by the presence versus absence of the second vowel /a/, the 2consonantal verbs like $(6 a, b, c)$ have identical forms for these stems. Thus while it is true that in general inflection does not alter the consonantal skeleton of a verb, the inflectional behaviour of a verb does reflect properties of its skeleton. Tables 1-8 are designed to display correspondences between the consonant skeleton, the vowel pattern and the inflectional behaviour of simple Silt'i verbs. These tables represent a near-surface taxonomy of the ca. 
Table 1. II-Verbs with a

Vowel Patterns and Inflection Consonant Skeleton

Example Perf. Imperf. Non-asp.

1. bala 'eat' (33) a $\quad$ a $\quad \emptyset \quad \mathrm{Ca}$ -

2. sače 'drink' (15) a $\quad$ a $\quad \emptyset \quad$ CP -

3. Tanže 'see' (2) a $\quad$ a $\quad 0 \quad$ CP $-\quad+$

4. Taje 'hit' (1) a $\quad$ a $\quad \emptyset \quad \mathrm{CP}$ - +

5. Pane 'do' (2) a $\quad$ a $\quad$ a $\quad$ CP -

Table 2. II-Verbs with a:

Vowel Patterns and Inflection Consonant Skeleton

Example Perf. Imperf. Non-asp.

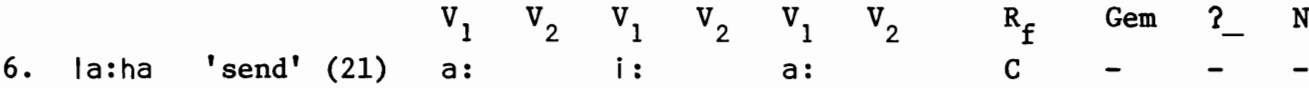

7. za:c'e 'watch' (2) a: $\mathrm{i}$ : $\mathrm{a}$ : $\mathrm{CP}$ - -

8. ra:je 'grow old' a: a: $a: \quad$ CP $\quad$ (3)

9. wa:ba 'give' (1) a: a: a: 
Table 3. II-Verbs with e:

Vowel Patterns and Inflection Consonant Skeleton

Example Perf. Imperf. Non-asp.

10. je:je 'reach' (10) e: $\begin{array}{lllllllll}v_{1} & v_{2} & v_{1} & v_{2} & v_{1} & v_{2} & R_{f} & \text { Gem } & \text { ? }\end{array}$ 11. k'e:ra 'watch' (5) e:

12. ?e:ma 'slander' (2) e:

13. he: da 'go' (2)

14. ?e:nza 'hold'

15. ?e:re 'reconcile' (1)

Table 4. II-Verbs with $O(:)$

Vowel Patterns and Inflection Consonant Skeleton

Example Perf. Imperf. Non-asp.

16. noze 'be angry' $\begin{array}{lllllllll}\mathrm{V}_{1} & \mathrm{~V}_{2} & \mathrm{~V}_{1} & \mathrm{~V}_{2} & \mathrm{~V}_{1} & \mathrm{~V}_{2} & \mathrm{R}_{\mathrm{f}} & \mathrm{Gem} & \text { ? }\end{array}$ (11)

17. '́'o:me 'be fat' (6) o: 0 u CP 0 e: e: $\mathrm{Ca}$ 
Table 5. III-Verbs with $a(:)$

Example

Vowel Patterns and Inflection Consonant Skeleton Perf. Imperf. Non-asp.

$\begin{array}{llllllllll}\mathrm{V}_{1} & \mathrm{~V}_{2} & \mathrm{~V}_{1} & \mathrm{~V}_{2} & \mathrm{~V}_{1} & \mathrm{~V}_{2} & \mathrm{R}_{\mathrm{f}} & \text { Gem } & \text { ? } & \mathrm{N}\end{array}$

22. k'atala 'kill' (84)

a $\quad$ a $\quad$ a $\quad \emptyset \quad \emptyset \quad$ a

23. ?adaga 'leave' (17)

a $\quad$ a $\quad$ a $\quad \emptyset \quad \emptyset \quad$ a

24. ?andara 'spend the

a $\quad$ a $\quad$ a $\quad \emptyset \quad \emptyset \quad a$

night' (6)

25. raw:at'a 'run' (1)

a $\quad$ a $\quad$ a $\quad \emptyset \quad \emptyset \quad$ a

26. jam:ara 'begin' (13)

a $\quad$ a $\quad$ a $\quad \emptyset \quad$ a $\emptyset$

27. ma:gada 'kindle'

(6) $a$ : $a$ a: $\emptyset$ a: $\emptyset$

28. da:b:ara 'thrive'

(1) $a: a$

a: $\emptyset \quad \mathrm{a}: \emptyset$

Table 6. III-Verbs with e: and o:

Vowel Patterns and Inflection Consonant Skeleton

Example Perf. Imperf. Non-asp.

$\begin{array}{lllllllll}\mathrm{v}_{1} & \mathrm{~V}_{2} & \mathrm{~V}_{1} & \mathrm{v}_{2} & \mathrm{v}_{1} & \mathrm{v}_{2} & \mathrm{R}_{\mathrm{f}} & \text { Gem } & ?_{-} \mathrm{N}\end{array}$

29. Je:bala 'dance' (20) e: a e: $\emptyset$ i: $\emptyset$ C $\quad$ -

30. ?e:wada 'tell' (6) e: a e: $\emptyset$ i: $\emptyset$ C $\quad$ - +

31. de:g:asa 'prepare a $\mathrm{e}:$ a $\mathrm{e}: \emptyset$ i: $\emptyset$ C + feast' (4)

32. ?e:nk'afa 'embrace' e: a e: $\emptyset$ i: $\emptyset$

33. t'o: l:aba 'beg' (6) $0:$ a $0: \emptyset$ : $\quad \emptyset$

34. $\mathrm{t}$ o:k'asa 'beg' (5) o: a $0: \emptyset \mathrm{u}: \emptyset$ 
Table 7. III-Verbs ending in CP

Vowel Patterns and Inflection Consonant Skeleton

Example Perf. Imperf. Non-asp.

$\begin{array}{lllllllll}v_{1} & v_{2} & v_{1} & v_{2} & v_{1} & v_{2} & R_{f} & \text { Gem } & ?_{-}\end{array}$

35. kirame 'chop' (3) a $\emptyset$ a $\emptyset \quad \emptyset \quad \emptyset \quad$ CP

36. firaj:e-y 'find' (1) a $\emptyset$ a $\emptyset \quad \emptyset \quad \emptyset \quad$ CP

37. bira:če 'disperse' a: $\emptyset$ a: $\emptyset$ a: $\emptyset$ CP

* The 3rd rather than the 2 nd consonant is geminated.

(For 4-radical verbs (IV), vowel position $\mathrm{V}_{1}$ and $\mathrm{V}_{2}$ are located between the 2nd and $3 \mathrm{rd}$, and between the $3 \mathrm{rd}$ and $4 \mathrm{th}$ consonant respectively; the position between the 1 st and 2 nd consonant is filled by epenthetic $i$ in accordance with the phonotactic constraints of the language.)

Table 8. IV-Verbs

Example

Vowel Patterns and Inflection Consonant Skeleton Perf. Imperf. Non-asp.

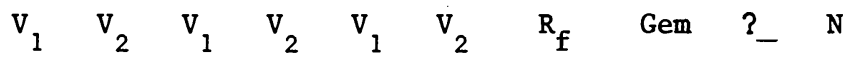

38. dinabat'a 'be sur- $\quad$ a $\quad$ a $\quad$ a $\quad \emptyset \quad \emptyset \quad \emptyset \quad$ C prised' (26)

39. sinat':ala 'know' (2)

(2) $\quad$ a $\quad$ a $\quad$ a $\quad \emptyset \quad \emptyset \quad \emptyset$

40. Iik'a:lak'a 'mix' (7) a: a a: $\emptyset$ a: $\emptyset$

41. ?imba:sasa 'stroke' (1) a: a a: $\emptyset$ a: $\emptyset$ C

42. k'unat'asa 'take a $a$ a $\quad \circ \quad \emptyset \quad \emptyset \quad \emptyset^{* *}$ C little' (4)

*The 3 rd rather than the 2 nd consonant is geminated.

${ }^{* *}$ The epenthetic vowel is $u$ rather than $i$. 
340 underived verbs on which this study is based, yielding 42 types. 5 The tables have been set up firstly according to the number of radicals of the verb root, and secondly according to the nature of the vowels, except for types 35 , 36 , and 37 which have been grouped together on the basis of their final radical.

Altogether, this classification makes use of 5 parameters for the consonantal skeleton and of 6 parameters for the vowel patterns in the different stem forms. The first consonantal parameter concerns the number of radicals in the verb stem and is specified by Roman numerals in the headings of the tables, ranging from II to IV. I am following here Bender and Hailu [1978:21] in their definition of a radical as a "CV sequence in a theme (or CCV if the consonant is geminate)", where the theme of a verb is understood to refer to the 3rd person masculine singular of the Simple Past tense of the verb. In adaptation to the Silt'i verb, the definition of a radical must be slightly widened, however, to allow for the special closed syllable type CVn to qualify as a radical as well. (See discussion of the feature ' $N$ ' below.) The sample verbs in the tables are cited in their theme form.

${ }^{5} \mathrm{~A}$ body of 340 verb roots is a comparatively small sample. However, this sample is based on a body of ca. 20,000 words of running texts, covering a variety of literary genres, such as folktales, proverbs, descriptions of cultural institutions, etc. From this body of texts, a computer concordance was printed out, and the 340 verb roots dealt with here are essentially the underived roots listed in the computer concordance. It is therefore hoped that the smallness of the sample is to some extent compensated for by the method of sampling. The following underived verbs contained in the data are not represented in Tables 1-8:

$\begin{array}{llll}\text { Perf. } & \text { Imperf. } & \text { Non-aspectual } & \\ \text { ba:la } & \text { ?ila:n } & \text { balo:t } & \text { 'say' } \\ \text { ca:la } & \text { ?ifla:n } & \text { ca:lo:t } & \text { 'know' } \\ \text { ?ala } & - & - & \text { 'exist' } \\ \text { mat'a } & \text { ?imac'a:n } & \text { mit:o:t } & \text { 'come' }\end{array}$

The idiosyncrasies of these verbs seem to require treatment of detail that lies outside the scope of this paper and have therefore not been included in the analysis here. 
The second parameter, " $R_{f}$ ", specifies the nature of the final radical of the verb stem, allowing for the three possibilities $\mathrm{C}, \mathrm{Ca}$, and $\mathrm{CP}$. Verbs ending in the C-type radical are the unmarked case. The consonant of the last radical is the final segment of the stem, and it is manifested on the surface only in one phonetic form, disregarding general assimilatory processes. Verbs with a Ca-type final radical have the special property that the vowel /a/ of that radical is part of the stem, rather than an inflectional suffix. This can be seen most easily in the 2nd singular masculine imperative form of the verb which does not take an inflectional suffix, e.g. bila 'eat!', as compared to wa:b 'give!' or k'ital 'kil1!'.6 Verbs of the CP-type are all subject to certain processes of palatalisation affecting the final radical. Two degrees of palatalisation can be distinguished here: in the weaker case, the palatalising influence can be seen only from the change effected in certain inflectional suffixes, typically the person marker $/-a /$ of the theme; added to weakly palatalising verbs, it surfaces as /-e/ (cf. types 16 and 20 in Table 4). In the stronger case, the suffix is palatalised as above, but in addition the final stem consonant is affected and surfaces generally as one of

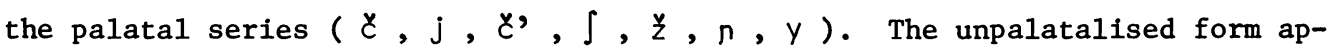
pears only preceding back vowels, e.g. sače 'he drank' and saku 'they drank' or siko:t 'to drink' (type 2).

The third skeletal parameter "Gem" concerns features of gemination, intended here to refer to consonant length. Only one consonant in a verb stem can be geminated, and if it is, then it can be only the consonant of the penultimate radical or of the last radical. More will be said below about the distribution of geminate consonants. It should be noted that Silt'i differs from many other Ethio-Semitic languages in that gemination is not used systematically to mark inflectional categories. ${ }^{7}$

${ }^{6}$ Other evidence for stem final /a/ can be obtained from interaction with various suffixes.

7 The only known exception to this rule concerns the two IV verbs sinat':ala 'know' (type 39), and mirak':ana 'get intoxicated by chewing qat': In both cases the non-aspectual stem is degeminated. The latter verb has another idiosyncrasy in that the vowel and gemination pattern of the imperf. stem and the stem form used for the 3rd person imperative are identical. 
The fourth parameter, marked as "? ", specifies the occurrence of a glottal stop as the initial consonant of the stem. 8

The fifth parameter, "N", refers to the occurrence of $/ \mathrm{n} /$ as the coda of the first radical of a stem. In almost all instances, the occurrence of this feature is restricted to radicals with / / / in onset position. The only known exception to this is the verb so:nc'e 'smel1'.9

The parameters chosen to characterise the vowel patterns and the inflectional behaviour of the verbs are restricted to specifying which vowel, if any, is found in the positions marked $v_{1}$ and $v_{2}$. For II and III verbs, these positions are quite straightforwardly the first and second vowel positions in the stem, i.e. the position between the first and second, and between the second and third consonant of the stem respectively. For IV verbs, however, $\mathrm{V}_{1}$ and $\mathrm{V}_{2}$ refer to the positions in the second and third radicals respectively. The reason here is that the first radical of IV verbs does not contain a lexical vowe1, but is given an epenthetic $i$ in accordance with the phonotactic constraints of the language, so that even IV verbs can be said to have no more than two vowels in their patterns. These vocalic parameters can range over the following values: $v_{1}$ of the perfective stem $/ a, a:, e:, 0,0: /$ and $\emptyset$; $\mathrm{V}_{2}$ of the perfective stem /a, $\mathrm{a}: /$ and $\emptyset ; \mathrm{V}_{1}$ of the imperfective stem /a, $\mathrm{a}:$, e:, $\circ, 0:, \mathrm{i}: /$ and $\emptyset ; \mathrm{v}_{2}$ of the imperfective stem /a, $\mathrm{a}: /$ and $\emptyset ; \mathrm{v}_{1}$ of the non-aspectual stem /a, a:, i:, $u: /$ and $\emptyset$; and $v_{2}$ of the non-aspectual stem /a, a:/ and $\emptyset$.

Equipped with these parameters and values, the analyst is next faced with the task of uncovering linguistically significant relations between them. In the strongest case, such an undertaking would yield a set of systematic statements capturing not only the relationships that hold between the parameters

${ }^{8}$ The phonological status of the glottal stop in Silt' $i$ is discussed in Gutt [1983].

${ }^{9}$ The peculiar distribution of the syllable with the structure ?Vn holds not only for verbs but also for other lexical categories in Silt'i. It was noted on historical comparative grounds by Leslau [1959] and Hetzron [1969], who suggested that this syllable type may historically have been derived from syllables beginning with a pharyngeal consonant. 
and values as found in the tables, but also delimiting the occurring combinations from the non-occurring, though logically possible, other combinations. Nothing of this degree of comprehensiveness is attempted here, however, partly because of the limited scope of a paper of this kind, and partly because the data base would not seem to warrant striving for exhaustiveness. Instead, what I shall attempt to do, is to choose a number of relationships which appear to be significant in that they allow a principled, and hopefully interesting, account of at least some of the major aspects of surface variety found in the data. The following relationships are believed to be significant:

(1) For all verbs, there are only two types of phonological processes involved in aspectual inflection: raising of the vowel in position $\mathrm{v}_{1}$, and omission of the vowel in $\mathrm{V}_{1}, \mathrm{~V}_{2}$, or both, taking the perfective stem to be (close to) the basic form.

(2) The only vowel that can be omitted in aspectual inflection is /a/ ; all other vowels either remain unchanged or get raised.

For convenience, from now on the first non-epenthetic vowel in the theme of a verb will be called its "thematic vowe1".

A closer examination of the data shows that there is a correlation between the two phonological processes involved in aspectual inflection and the nature of the thematic vowel, suggesting a division of the underived Silt'i verbs into two broad classes, with two subclasses each.

Class 1: All verbs with the thematic vowel /a/. These class 1 verbs are inflected for aspect by vowel omission alone, according to the following patterns:

Perfective Imperfective Non-aspectual

(C) $\mathrm{CVC}(\mathrm{VC}) \quad(\mathrm{C}) \mathrm{CVC}(\mathrm{C}) \quad \mathrm{CC}(\mathrm{VC})$

$\operatorname{ccc}(\mathrm{C})$

Subclasses:

1a: II and III-C verbs (these verbs do not have the leftmost, optional consonant shown in the inflectional patterns above and take the upper pattern for the non-aspectual form).

1b: III-CP and IV-verbs (these verbs do have the leftmost, optional consonant and take the lower pattern for the non-aspectual form). 
Class 2: All verbs with a thematic vowel other than /a/. In general, class 2 verbs are inflected for aspect by a combination of vowel raising and vowel omission which takes the following patterns:

$\begin{array}{lll}\text { Perfective } & \text { Imperfective } & \text { Non-aspectual } \\ \text { (C) CVC(VC) } & \text { (C) CVC (C) } & \text { (C) CVC (C) }\end{array}$

Subclasses:

2a: Non-low thematic vowe1 (II and III verbs with /e:/ or /o:/ ; these verbs raise the thematic vowel in the non-aspectual stem).

2b: Low thematic vowel (II, III, and IV verbs with /a:/; these verbs do not raise the thematic vowel in any of their stems).

According to this scheme, the 42 verb types represented in the Tables 1-8 above belong to the following classes: types 1-5 and 22-26 belong to class 1a; types $35,36,38,39$, and 42 belong to $1 b$; types 10-21 and 29-34 fall into class $2 \mathrm{a}$, and types $6-9,27,28,37,40$, and 41 into class $2 b$.

This comparatively simple, informal account of aspectual inflection for Silt'i verbs is, however, not completely accurate in the following respects: first, regarding basic relationship number 1 , pointed out on page 196, there are at least two other phonological processes that cooccur with raising and omission for a small number of verbs. One of these is degemination, referred to already above in note 7 , and the other is vowe1 shortening, found in type 18. Neither of these processes upsets the system itself, but is subsidiary to it. More seriously, the present account makes the wrong predictions for types $5,26,6$, and 7 . In the case of type 5, its class membership in la predicts the omission of the thematic vowel in the non-aspectual stem-wrongly, because this type maintains its thematic vowel throughout. Similarly, type 26 is predicted to omit, the thematic and maintain the non-thematic vowe1 in the non-aspectual stem, whereas the actual situation is the reverse of the prediction. The thematic vowel is maintained, and the non-thematic vowel omitted. Types 6 and 7 have again a different problem. Generalisation $2 b$ predicts that they are exempt from raising throughout their inflection, but in both types in the imperfective stem the thematic $/ a: /$ is raised to /i:/ .

Despite these deficiencies-and most of them could probably be overcome in 
a fairly straightforward manner-one might defend the account given above as a fairly good approximation to the facts and as a fairly simple one at that. However, a closer look at the generalisations made in it reveals that there are still more correlations to be captured.

Turning to the inflectional patterns of the imperfective stem first, a comparison of the three patterns $1 \mathrm{a}, 1 \mathrm{~b}$, and 2 which were postulated reveals a very obvious similarity:

(7)

$\begin{array}{lrr} & \text { Perfective } & \text { Imperfective } \\ 1 \mathrm{a} & \operatorname{cVc}(\mathrm{VC}) & \operatorname{cVC}(\emptyset \mathrm{C}) \\ 1 \mathrm{~b} & \operatorname{CCVC}(\mathrm{VC}) & \operatorname{ccVc}(\emptyset \mathrm{C}) \\ 2 & (\mathrm{C}) \operatorname{CVC}(\mathrm{VC}) & (\mathrm{C}) \operatorname{cVC}(\emptyset \mathrm{C})\end{array}$

This similarity could be expressed in the following simple rule:

(8) For imperfective formation, omit the rightmost non-thematic vowel (of the perfective stem).

Given the perfective stem as a base, this rule (8) accounts for the formation of the imperfective stem for all types except 6 and 7 . However, a simple rule of the following kind could take care of these exceptional cases, too:

(9) In verbs of types 6 and 7 , front-raise the thematic $/ a: /$ to $/ i: /$ in the imperfective stem.

Since there is nothing in the structure of these two verb types that would separate them from other types, (9) would have to be a minor phonological rule, triggered by an appropriate rule diacritic associated with these verbs in the lexicon. ${ }^{10}$ Rules (8) and (9) together, then, would provide an explicit description of imperfective stem formation for all 42 types listed.11

${ }^{10}$ An alternative solution avoiding a rule diacritic would be to have $/ \mathrm{i}: /$ rather than /a:/ in the underlying representation of these verbs. For an evaluation of this solution see note 20 below.

${ }^{11}$ There is, in fact, one other exception, and that is type 42, where the thematic vowel in the imperf. is not $/ a /$, but $/ 0 /$. There seems to be a fairly simple explanation for this exception: verbs of type 42 are subject to "labialisation"; their epenthetic vowel is always /u/ rather than /i/, and this could explain also the occurrence of $/ o /$ rather than $/ a /$, assuming that the labialisation applies to this vowel as well. 
Concerning the formation of the non-aspectual stem, the situation is somewhat more complex, but again further generalisations can be made.

$\begin{array}{rrr} & \text { Perfective } & \text { Non-aspectual } \\ 1 \mathrm{a} & \mathrm{CVC}(\mathrm{VC}) & \mathrm{C} \emptyset \mathrm{C}(\mathrm{VC}) \\ 1 \mathrm{~b} & \operatorname{ccVC}(\mathrm{VC}) & \mathrm{CC} \emptyset \mathrm{C}(\emptyset \mathrm{C}) \\ 2 & (\mathrm{C}) \operatorname{cVC}(\mathrm{VC}) & (\mathrm{C}) \operatorname{cVc}(\emptyset \mathrm{C})\end{array}$

The similarities between these three patterns could be captured by the following two rules:

(11) For all verbs of Class 1, omit the thematic vowel for the formation of the non-aspectual stem.

(12) For all verbs of Classes $1 \mathrm{~b}$ and 2, omit the rightmost non-thematic vowe1 for the formation of the non-aspectual stem.

Rules (11) and (12) correctly express the regularities of non-aspectual stem formation as displayed in (10), but there is substantial overlap between (8) and (12), which would suggest that a significant correlation has still been missed. More specifically, (8) and (12) involve the same structural change, but for different verb classes and stems. Breaking the categories imperfective, perfective, and non-aspectual down into feature representations can solve this problem.
Perfective
[ + perfective]
Imperfective
[ - perfective]
[ - imperfective]$$
\text { [ + imperfective] }
$$
Non-aspectual
[ - perfective]
[ - imperfective]

Given this feature representation, (8), (11), and (12) could be replaced by (14) and (15) below:

(14) Omit the rightmost non-thematic vowel of Class $1 \mathrm{a}$ in the environment [+ imperf] and of Classes $1 b$ and 2 in the environment [- perf].

(15) Omit the thematic vowel of Class 1 in the environment $\left[\begin{array}{l}- \text { imperf } \\ - \text { perf }\end{array}\right]$.

One further rule would be needed to predict the raising of non-low vowels for the non-aspectual stem of Class 2 verbs:

(16) Raise all non-low vowels in the non-aspectual stem. 
Rule (16) can stand in this general form because the reference to non-low vowels automatically restricts its application to Class $2 a$. Thus, given the perfective form of the verb, rules (9), (14), (15), and (16) together would give a good account of the inflectional system. However, even this fairly simple rule system seems to be unsatisfactory in a number of respects: (i) it makes incorrect predictions for types 5 and 26; (ii) by using the two distinct labels "non-thematic vowel" and "thematic vowel" in (14) and (15) respectively, the system obscures the fact that omission in all cases involves only one vowel, i.e. /a/ ; (iii) postulating the omission of a "thematic vowel" in (15) seems somewhat counterintuitive. Seeing that drawing a distinction between "thematic" and "non-thematic" vowels is not really satisfactory, let us suppose that the following distinction is made:

(17) All occurrences of (non-epenthetic) vowels in verb stems belong to one of two classes, occurrences which are fully specified in the lexicon (more simply "specified vowels") and occurrences which are not fully specified in the lexicon ("unspecified vowels").

An unspecified occurrence of a vowel is one which, in a SPE-type feature system, would be marked only as $\left[\begin{array}{l}+s y 11 \\ -c o n s\end{array}\right]$ without any further distinctive features being indicated. A specified occurrence of a vowel is one which contains a complete distinctive feature matrix.

Let it be assumed further that there is the following convention:

(18) Only unspecified vowels can be omitted in inflection.

And lastly, let us suppose that there is a general rule which, at an appropriate stage in the phonological processing, specifies all surviving unspecified vowels as $/ \mathrm{a} /$. Provided there was a theory which could handle such stipulations, one could in principle devise a rule system in which the three objections made to the last rule system would be met. The fact that the "thematic vowel" in types 5 and 26 is not omitted could easily be accounted for under the assumption that for these verbs, the vowel /a/ is exceptionally specified in the lexicon. For all other cases, this system would incorporate a simple explanation of the fact that only /a/ seems to be liable to omission in the inflectional processes, and lastly it would also make unnecessary the 
implausible suggestion of having "thematic" segments omitted. In Part 4, a solution will be suggested which can take care of exactly these points.

4. A Multi-tiered Analysis

Any theory that expresses the generalisations outlined in the closing paragraph of Part 3 must crucially have the ability to draw a principled distinction between lexically specified and lexically unspecified vowels. The "most extreme version of autosegmental theory" [McCarthy 1982b:72] seems to be designed to do just this: "This view holds that the segmental tier contains on1y information about the canonical pattern of a form, encoded as a string of $C^{\prime} s$ and V's. All features for point and manner of articulation appear on a separate tier or tiers, as in the representation of Arabic kattab 'caused to write' in [19]:"

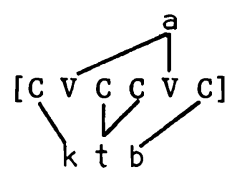

\section{(ibid.)}

Consequently, what follows is based largely on the theory proposed in McCarthy [1981, 1982a], supplemented by the autosegmental theory of the syllable proposed by Clements and Keyser [1981]. Modifications to both theories will be proposed in the course of this study. In section 1 of this part, I shall discuss the nature of the lexical specifications required as a base for the inflectional processes, and in section 2 I shall return to the formalisation of the inflectional processes themselves.

4.1. Lexical specifications. The discussion here will be restricted to specifications for underived verbs. McCarthy [1981: 376] proposed to define a morpheme as "an ordered string of 1 x $n$ feature matrices associated autosegmentally with a root node $\mu . "$ He illustrates this by the following diagram:

$$
\left[\begin{array}{c}
+F_{1} \\
-F_{2} \\
\vdots
\end{array}\right]\left[\begin{array}{c}
-F_{1} \\
-F_{2} \\
\vdots
\end{array}\right] \quad \ldots \ldots\left[\begin{array}{c}
+F_{1} \\
+F_{2} \\
\vdots
\end{array}\right]
$$

[McCarthy 1981:377] 
Based on this approach to the morpheme, McCarthy introduces a new kind of autosegmental tier: "Since a morpheme ... is a set of feature matrices dominated by a single node $\mu$, we can say that a morphologically defined tier contains all and only the feature bundles that are daughters of a single $\mu$ " (p. 383, emphasis mine-EAG). Given the freedom of assigning feature complexes to different tiers which can then be associated with one another, it is of great importance for autosegmental theory to build in sufficient constraints.

In autosegmental phonology proper, one such constraint was the stipulation that "the autosegmentalisation of some feature or bundle of features defines a single tier on which all and only those features are represented" [McCarthy 1981:383]. This strong stipulation would demand the following bidirectional relation: a tier $T_{n}$ was to contain only the features of the set $F f_{1}, f_{2}, \ldots$ $\left.f_{j}\right\}$, and conversely, any feature $f_{i} \in F$ was to occur only on tier $T_{n} \cdot$ McCarthy's introduction of morphologically defined tiers weakened this constraint in a fairly obvious way, viz. the second stipulation that any distinctive feature could occur on only one tier had to be abandoned. Nevertheless, McCarthy upholds that "the original definition of an autosegmental tier is not supplanted in this model. Only one set of phonological features can appear in any column of a particular tier. Moreover, different tiers cannot contain the same features unless those tiers represent different morphemes, and then only if a particular grammar stipulates that the tiers are morphologically determined" (p. 383, emphasis mine-EAG). It would seem that the main aim both of the original constraint and the weaker version of McCarthy was to avoid conflicting associations as represented schematically in (21).

$$
\begin{array}{r}
{\left[\begin{array}{c}
\vdots \\
+F_{i} \\
\vdots \\
i
\end{array}\right]} \\
{\left[\begin{array}{c}
\vdots \\
-F_{i} \\
\vdots
\end{array}\right]}
\end{array}
$$


The traditional constraint ruled such associations out in a very simple way: an association of features $\left[+F_{i}\right]$ and $\left[-F_{i}\right]$ could never arise, simply because $F_{i}$ would be represented on one tier only, and association could take place only between different tiers. McCarthy's constraint relies on the additional assumption that morphemes never enter into a direct associative relationship with each other, and therefore again a direct association of feature $\left[+F_{i}\right]$ of morpheme $X$ and a feature $\left[-F_{i}\right]$ of morpheme $Y$ could not arise. Given that the intended effect of these constraints is to avoid a configuration of the type shown in (21), it would seem advantageous to replace the more specific constraints by the general condition (22):

(22) Any direct association between tiers that share one or more features is ill-formed.

The restriction of this condition to direct association is important, because indirect association is in fact one of the strong points of the autosegmental approach, both for phonology and morphology. In both cases a "neutral" tier mediates the association between conflicting or overlapping autosegments, as schematised in (23). 12

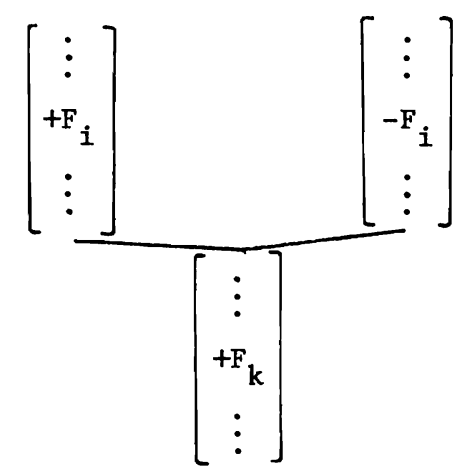

After this brief preparatory discussion, we can now consider the form of the lexical entries. We sha1l assume that each entry is of the following form:

${ }^{12}$ Note that one of Goldsmith's [1979:23] paradigm cases for the justification of autosegmental phonology is his analysis of contour tone on short vowels by associating two (conflicting) pitch levels with one segment. 
it contains a $\mu$-feature complex which is associated obligatorily with a consonant tier, in some entries also with a vowel tier and/or a nasal tier, which will be discussed below. Long segments are associated already in the entry with the CV- and syllable tiers. In all cases, the lexical entry itself is restricted to contain idiosyncratic information only. As an example, consider the lexical entry of the verb ?e:wada 'tell' as presented in (24):

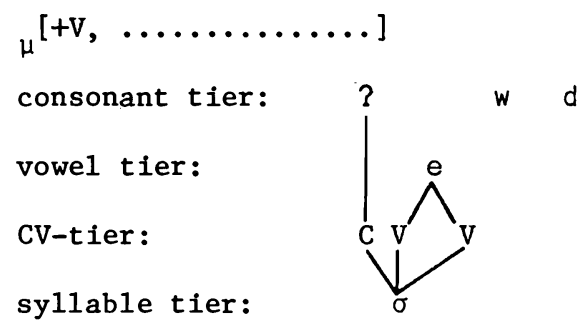

Several comments are in order here. First of all, the geometrical arrangement of the tiers in (24) (and all subsequent mu1ti-tiered diagrams) is of no theoretical significance; in particular, for one tier to be drawn above another does not imply a relation of dominance. Secondly, the point of the preparatory discussion should be clear now: the configuration shown in (24) violates both the original constraint and McCarthy's extended constraint, but is well-formed in terms of (22). The vowel and the consonant tier share features, but are not directly associated with one another. Thirdly, the use of the symbols "e ", "?", etc. is slightly misleading in that the entry does not contain the fully specified feature matrices one would normally relate to these symbols, but only "archisegments" which "provide a11 the information needed to distinguish consonants from one another by point and manner of articulation" [McCarthy 1981:387] without reference to the features [segmenta1] and [sy11abic]. Following McCarthy, these two features are supplied by association with the CV-tier (or "prosodic template"), sometimes also referred to as CV-skeleton [Ha1le and Vergnaud 1980]. 13 The CV-tier is composed solely of the features [syllabic] and [segmental].

13 This approach implies that the feature [sy11] is not really a part of the phonetic description of the sounds but belongs to the phonotactic subcom- 
With Clements and Keyser [1981:17] I assume that "the elements of the CVtier are interpreted as corresponding to the timing units of speech-production at the sub-syllabic level. Thus, a single $C$ represents a single unit of timing, while a sequence CC represents a double timing unit" (cf. the association pattern of the long vowel in (24) above).

In addition to the entries, the lexicon is assumed to contain, among others, the following redundancy conditions and rules pertaining to the syllabification of verb roots: firstly, each autosegment on the consonant tier must be associated with exactly one $\sigma$-node on the syllable tier via the CV-tier. Secondly, each $\sigma$-node must be associated with a sequence $C \mathrm{~V}$ on the CV-tier, unless the entry itself already specifies some other association. These two conditions ensure that each root consonant gets expanded into a radical. Thirdly, autosegments on the consonant tier associate with [-syllabic] positions and autosegments of the vowel tier with [+syllabic] positions of the CVtier. (This last convention presupposes that the phonology of the language stipulates for each autosegment to which tier it belongs; I suggest that each autosegment must be a member of at least one tier, but may hold membership on more than one tier.)

Apart from these more general conditions, provision needs still to be made for verbs with a "nasal syllable". i.e. verbs with a positive value for the parameter "N". Structurally, this nasal syllable is of the type CVn, where (with very few exceptions) the onset of the syllable is manifested by / / . Distributionally, the occurrence of this syllable is restricted to the initial

ponent of the grammar, which is the one containing a theory of the syllable. As far as the phonetic inventory of a language is concerned, this would predict that no two sounds can be distinguished by the features [sy11] alone. Thus, provided that there is no genuine phonetic difference, like friction, between them, the phonemes / $i /$ and / $/$ / would be represented only by one underlying autosegment, the assignment of the correct value of the feature [sy11] following from their tier-membership. Anderson [1981:518] also adopts a positional interpretation of the feature syllabic, though in a different framework: "... [+sy11abic] segments are precisely those which are elements of $\mathrm{N}$ [= nucleus-EAG], while [-syllabic] segments are those (perhaps identical in all other features) which are members either of 0 [= onset-EAG] or of $\mathrm{M}[=$ margin-EAG]." 
position of words in underlying representations, both for nouns and verbs alike. (Cf. note 9 for historical observations.) While it will be assumed that in the unmarked case syllabification will be in terms of open syllables, a convention attractive from the point of view of evaluating a grammar, nasal syllables will necessarily be closed. Simple representation of the nasal element as $/ \mathrm{n} /$ on the consonantal tier would be insufficient in at least two respects: it would upset the matching process, and it would fail to predict the word initial closed syllable. The best solution at present seems to be to postulate an additional autosegmental "nasal tier", containing the archisegment corresponding to $/ \mathrm{n} /$ as its sole element. In case a verb (or other word) is marked to have this nasal melody, a special convention would stipulate that for this entry the initial syllable has to be a closed one and that the nasal element is to be associated with the coda of that closed syllable.

One further language-specific constraint would need to be imposed on the CV-tier, and that is the restriction that III-CP verbs and IV verbs do not have a vowel in their first radical. Assuming that III-CP verbs are underlyingly IV verbs, the constraint could simply stipulate the deletion of the first vowel position of a CV-tier associated with a 4-syllabic syllable tier.

As just hinted, the lexical representation of the " $R_{f}$ " parameter, more specifically of the Ca- and CP-type verbs, still needs to be dealt with. Taking as a clue that their inflectional behaviour groups III-CP verbs together with IV verbs, it seems obvious to assume that underlyingly III-CP verbs are in fact IV verbs with some special property. This solution is supported by the fact that III-CP verbs do not fit the gemination pattern of any of the other verb classes. All other verbs that have gemination have their penultimate consonant geminated; only III-CP verbs have their last consonant geminated. This fact could be explained easily if underlyingly there was a fourth consonant.

Given this set of facts for III-CP verbs, it seems natural to posit an underlying additional radical for all CP-type verbs. This analysis is then again confirmed by the absence of IV-CP verbs, which would have been problematic since it would predict the existence of underlying V-verbs, not found elsewhere in the language. What then is the special property of CP-verbs, leading to the loss of their final radical in the surface representations? One relevant ob- 
servation here would be that there do not seem to be any verbs in the language that have $/ y /$ as a final consonant in their underlying representations with the $/ y /$ surfacing as such. 14 In other words, there are verbs that have / $/$ underlyingly, but it does not surface, and there are verbs with $/ y /$ on the surface in final position, but underlyingly that $/ y /$ is something else.15 Based on these observations, it would seem reasonable to assume that underlyingly, CP-verbs have an additional / $/ \mathrm{f}$ as their stem final consonant. Thus, the consonant tier of the verb sače 'drink' would be $s k y$. Given such an underlying representation, two facts would still need to be accounted for: one, that the surface form lacks a third syllable, and two, that the final surface syllable is palatalized, both in its vowel and consonant. This could be achieved by the following rules.

\section{Palata1 Syllable Deletion}

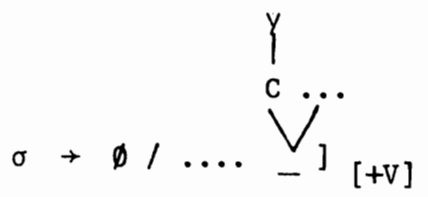

This rule would effect the deletion of a verb-final syllable node that was associated with the semivowel $/ y /$, or more correctly with the corresponding twotiered configuration, as shown in (25). Some further general convention could be assumed which would delete any CV-tier material not associated with a syllable node. This would then leave the autosegment free for reassociation, the most 1ikely candidates being the CV-tier immediately to its left. It will be recalled that there are two kinds of CP-verbs, those where the vowel alone of the final radical is affected and those where both the consonant and the vowel

${ }^{14}$ The notation $/ y /$ is an abbreviation of the 2-tiered configuration

${ }^{15} \mathrm{Cf}$., for example, ?afo:ye 'he rested' (derived verb). In these instances there is clear evidence that the $/ y /$ has a different underlying source, being derived by a process of palatalisation from underlying /// which still surfaces preceding back vowels, e.g. in the infinitive ?afu:lo:t 'to rest'. 
are palatalized. The weaker case might be accommodated without any further rule, bearing in mind that after Palatal Syllable Deletion, including the deletion of the corresponding CV-material, the following configuration is left:

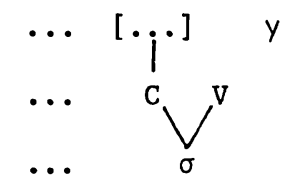

Since the autosegment of $/ y /$ is, in fact, identical to the autosegment of $/ \mathrm{i} /$, this autosegment would be reassociated automatically by the general association conventions with the still unassociated V-position to its left, so that now the stem would end in the vowel / $i /$. Since a rule changing a sequence $/ \mathrm{i} / \mathrm{t} / \mathrm{a} /$ into $/ \theta /$ is needed independently, this solution seems adequate for the weak palatal verbs at least. The strong palatal verbs would need an additional minor rule palatalizing the consonant of the new final syl1able. An appropriate rule diacritic, e.g. [tpal], would have to be included in the $\mu$-feature complex of such verbs.

Assuming that the CP-verbs can be taken care of in a way similar to that outlined above, this leaves the Ca-verbs and the C-verbs. One solution would be for the Ca-verbs to be derived in a manner parallel to that of the CP-verbs, i.e. by postulating an additional underlying final radical, this time, however, the glide /h/. This approach has been chosen for Amharic by Bender and Hailu [1978]. For Silt'i, however, this type of solution seems less well motivated, and in fact, there appears to be a fairly straightforward solution favoured by the syllabification theory adopted here. Given that the unmarked syllabification process works in terms of open syllable expansion, the most highly valued grammar would be one that used open syllables throughout, and any grammars using other syllable types would be more costly.

In Silt' $i$, the most common verb type is that ending in a consonant rather than in an open syllable, and so one would expect this feature to be included in the grammar at special cost. A very simple solution would be to assume that a lexical filter would rule out all verb stems with an unassociated stemfinal vowel. Note that this filter would not impinge on CP-verbs because 
their final V-slot is associated with an autosegment. Ca-verbs, in turn, again complicate the grammar in that they do not follow the general structure of the Silt'i grammar, though being closer to the universally simpler type. Both these properties could be expressed in the grammar if these verbs were marked diacritically as exceptions to the language-specific " $R_{f}$ "-Filter proposed above. No special rule would be needed to form these verbs since they conform to the universally favoured type, and yet they do incur some complication of the grammar by requiring diacritic marking in the lexicon. 16

It will be assumed then that the association with appropriate CV-tiers can be taken care of along the lines of a syllable theory sketched above. Returning to the autosegmental tiers, it should be noted that each of these tiers has its own constraints regarding the set of autosegments it may contain (its "vocabulary"), regarding the ways in which these autosegments can combine to form a "melody" (its "syntax") and regarding the manner of association with other tiers. Without getting into too much detail, I shall briefly outline some of the more important constraints. Syntactic constraints on the consonant tier would be that $/ ? /$ can occur only as the leftmost element of a melody, that no melody may contain more than two identical autosegments, and that no two autosegments in a single melody may differ from each other only in either voicing or ejectiveness. Also, no melody may contain less than two or more than four autosegments. Some of these constraints will, in fact, hold.for consonant tiers in general, not only for those of verbs. The vowel tier in verb entries has maximally one autosegment in a melody, and no melody on this tier may have the feature [thigh]. Likewise, the nasal tier allows only one autosegment as a melody. Each lexical entry must have a consonantal melody, but may or may not have either a vocalic or nasal melody. Each of these tiers associates directly with the CV-tier.

On the basis of these assumptions about the lexical entries and their sy1labification, the verbs k'atala 'kill', ?e:nk'afa 'embrace', and bira:c'e

${ }^{16}$ In a more comprehensive grammar of Silt'i, covering not only aspectual inflection, but also person-number-gender inflection, the argumentation may turn out to be more complex; however, it should proceed along the same general lines. 
'disperse' are treated in the lexicon as shown in (27-29).17

(27) k'atal- 'kill'

Entry: $\quad \mu^{[+V, \ldots \ldots . ' k i l 1 ']}$

Consonant tier: $k^{\prime} t$ l

Syllabification:

Consonant tier:<smiles>[Y][CH][CH]I</smiles>

CV-tier

Syllable tier:

$V_{\sigma}^{C V} V_{\sigma}^{C V} \bigvee_{\sigma}^{C X} R_{f}^{-F i l t e r}$

(28) ?e:nk'af- 'embrace'

Entry: $\quad \mu^{[+V}, \ldots \ldots$ 'embrace' ]

Consonant tier:

Vowel tier:

Nasal tier:

CV-tier:

Sy1lable tier:

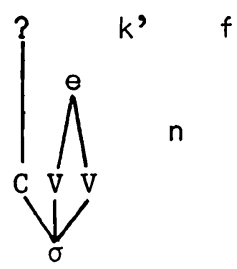

Syllabification

Consonant tier:

Vowel tier:

Nasal tier:

CV-tier :

Syllable tier:

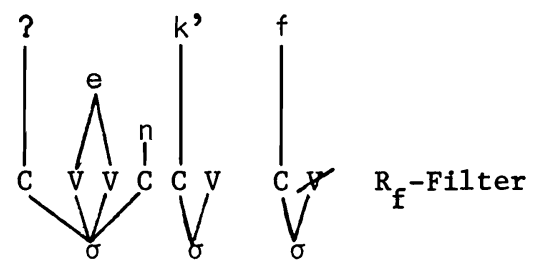

17 From now on $I$ shall use the following notational conventions in diagrams of multi-tiered configurations.

1. Autosegments are represented by their corresponding phonetic symbols.

2. The notation [ ... ] represents the presence of any autosegment at all.

3. Deletion of points of structure is indicated by a slanted line through the corresponding symbol(s) at the appropriate stage of derivation. 
(29) bira: ¿’'- 'disperse'

Entry: $\quad \mu^{[+V, \ldots+p a l ~ ' d i s p e r s e ' ~] ~}$

Consonant tier: b $r \quad t$, i

Vowel tier:

CV-tier:

Syllable tier:

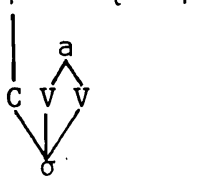

Syllabification:

Consonant tier:

Vowel tier:

CV-tier:

Syllable tier:

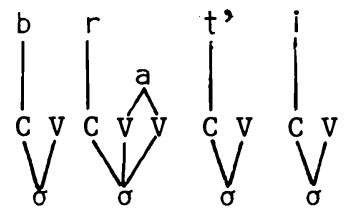

After palatal syllable deletion and reassociation:

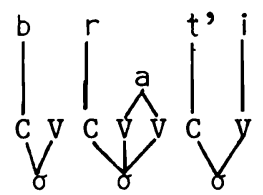

4.2. Aspectual inflection. Assuming that lexical representations of the kind developed in Section 4.1 are available, the discussion of a proper representation of inflectional processes in a multi-tiered framework can now be continued. For convenience, the inflectional patterns are again displayed here in (30):

(30)

$$
\left[\begin{array}{l}
\text { tperf } \\
\text {-imperf }
\end{array}\right] \quad\left[\begin{array}{l}
\text {-perf } \\
+ \text { imperf }
\end{array}\right] \quad\left[\begin{array}{l}
\text {-perf } \\
\text {-imperf }
\end{array}\right]
$$

1a) $\operatorname{cVC}(\mathrm{VC})$

$\operatorname{cvc}(\emptyset \mathrm{c})$ $\mathrm{C} \emptyset \mathrm{C}(\mathrm{VC})$

1b) $\operatorname{ccvc}(\mathrm{VC})$ $\operatorname{ccvc}(\emptyset \mathrm{C})$ $\operatorname{cc} \varnothing \mathrm{c}(\emptyset \mathrm{c})$

2) (C) $\mathrm{CVC}(\mathrm{VC})$

(c) $\operatorname{cvc}(\emptyset \mathrm{C})$

(C) $\operatorname{cvc}(\emptyset \mathrm{C})$

As before, I shall assume that the underlying representation yields the perfective stem without undergoing any special processes of aspectual inflection. This seems advantageous firstly because the CV-pattern of the perfective stem is closest to that resulting from unmarked, open syllable expansion 
and secondly because the formation of the other two stems then needs only two types of phonological process, i.e. vowel raising and vowel deletion.

Beginning with the informal inflectional rules (14) and (15), any attempt to convert them into formal rules will reveal a problem in that rule (14) takes as input two classes of string that do not really form a natural class in terms of their structure, $1 . e$. structurally, $1 \mathrm{~b}$ would be closer to class la than to class 2. In this respect, the theory proposed here seems to make the right predictions: it would not easily allow formulating a rule combining these two classes.

Another tempting solution would be to capture the very obvious regularity that with the sole exception of the non-aspectual stem of class la all [-perf] stems have their rightmost, non-thematic vowel deleted. A second rule could then simply delete the leftmost (thematic) vowel in the non-aspectual stem for unspecified verbs, the lexically specified ones being protected by some appropriate convention. The only condition would be that the exceptional form of class la could be taken care of in some non-arbitrary manner. This, however, again turns out to be a problem. Apart from these problems of formalisation, one would be reluctant to adopt an approach which makes the numerically strongest class of the system the exception rather than the rule. Seeing these difficulties of reducing the inflectional processes to a single system, it seems natural to suppose that there might be at least two different systems at work, one pertaining to class 1 and one pertaining to class 2 . In outline, the two systems have the following properties. System 1 operates only in terms of CVpatterns, and makes a three-way distinction of the following kind:

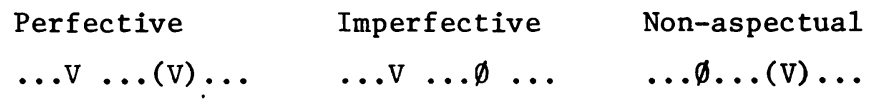

Given two vowel-slots in a verb, this would seem to be a very efficient way of marking a 3-way distinction, and this is in fact the pattern displayed by the strongest single class in the data. From a historical point of view, this system, referring to CV-patterns only, seems quite in line with the "typical" Semitic behaviour of verbs, if one takes, for example, the system of Classical Arabic as a typical member of the set. 
System 2 would be different in kind, in that it replaces part of the pattern inflection by ablaut distinctions, typically vowel raising. Thus, the Perfective vs. non-Perfective distinction is made in terms of CV-patterning, and the Aspectual vs. Non-aspectual distinction is made in terms of vowel raising, taking III verbs to be the most typical forms of verbs. This system is outlined in (32):

$$
\begin{aligned}
& \text { Perfective Imperfective Non-aspectual } \\
& \ldots v \ldots(v) \ldots \quad \ldots v \ldots \emptyset \ldots \quad \ldots v \ldots \emptyset \ldots \\
& \text { [thigh] }
\end{aligned}
$$

Assuming these two regular systems, class $1 b$ would fall out as the exception, which seems a much more natural result than the solution considered above. 18

The formal representation of these two systems can be given in terms of the following set of rules. Figure 1 first of all presents the rule schema that will take care of the CV-pattern inflection. Other rules will deal with the ablaut processes of class 2. From a formal point of view, rules (33-36) (next page) seem to form a fairly homogeneous rule schema, referring only to the phonotactic properties of verb roots, irrespective of any of their phonetic qualities.

Beginning with rule (33) of Figure 1, this rule takes care of all CV-tier adjustments in Class 2 . This class is singled out by the prespecified vowel in the antepenultimate syllable, represented in Figure 1 by the empty bracket associated with the $\mathrm{V}$-slot of that syllable. The rule then says that the vowel slot of the penultimate syllable is to be deleted, and the rule is to apply both to the imperfective and non-aspectual stems, as indicated by the [-perf] feature.

Rules (34-36) then deal with the verbs of class 1: Rule (34) with the imperfective stem, and rule (35) with the non-aspectual stem. Rule (36) takes care of the additional deletion required for class 1b. (Cf. note 18.) Rule

${ }^{18}$ Strictly speaking, only the "genuine" IV verbs of this class present a problem, since the III CP verbs do not have any non-thematic vowel that would need deletion at this point. 
Figure 1. Schema for CV-pattern verb inflection

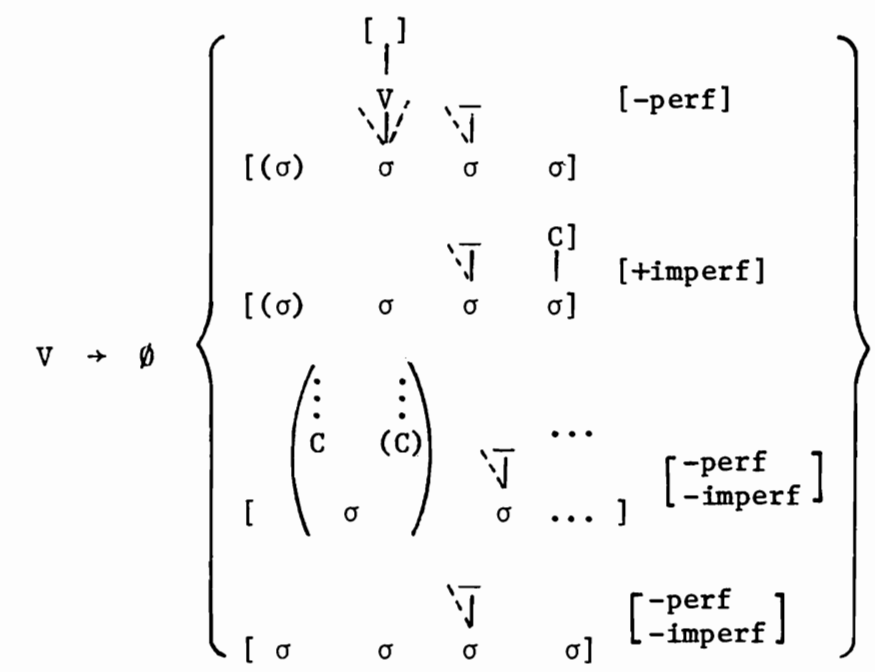

(34) deletes the vowel slot of the penultimate syllable of unspecified III and IV verbs in the Imperfective tense. Note that the rule specifies that the last syllable end in a consonant only. This serves to exempt III-CP verbs from having their thematic vowel deleted in case it is lexically unspecified. Rule (35) deletes the lexically unspecified, thematic vowel of II, III, and IV verbs in the non-aspectual stem. This is achieved by the disjunction of two rules which delete any unspecified vowel found either in the 2nd syllable of IV and III-CP verbs (marked by the absence of a vowel in the 1st syllable) or in the 1st syllable of II and III verbs. Rule (36) achieves the exceptional deletion of the non-thematic vowel slot in lexically unspecified IV verbs in the nonaspectual stem (class 1b). ${ }^{19}$ The ablaut-adjustments are taken care of by the following rule schema:

${ }^{19}$ Rule (46) also applies vacuously to the non-aspectual stems of Class 2. 
(37)

Inflectional Raising

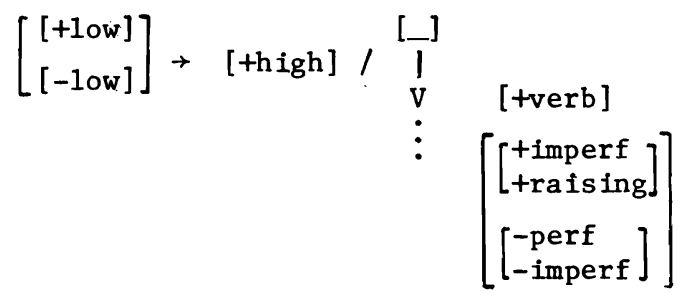

This schema abbreviates two processes of inflectional raising. The upper row in the brackets raises the underlying /a:/ to /i:/ in the imperfective stem of types 2 and 15, the process being triggered mainly by the rule diacritic [+raising] while the lower row accounts for the raising process taking place in the non-aspectual stem of all verbs of class $2 a .20$

The last major rule concerning aspectual inflection is (38).

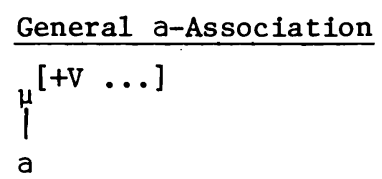

Rule (38) associates the autosegment corresponding to $/ a /$ with all $\mu$-nodes specified as $[+V]$, i.e. with all verbs. By the general association conventions, this vowel melody will be associated with all remaining, unspecified V-slots of the CV-tier. 21

The outworking of the inflectional rules is illustrated in (39-44) below by the verbs k'atala 'kill', e:nk'afa 'embrace', bira:će 'disperse', the lexical entries and syllabified forms of which were already given above in (27-

${ }^{20}$ As $\mathrm{Dr}$. R. Hudson pointed out to me (cf. note 10 above) a rule diacritic would not be needed if the underlying vowel of verbs of types 6 and 7 were $/ \mathrm{i}: /$ rather than $/ \mathrm{a}: /$. However, that solution would seem to increase the complexity of the overall analysis in the following respects: both solutions would introduce a phonological process of vowel lowering not needed otherwise in addition to that of vowel raising, and they would also make the verbs of types 6 and 7 exceptional to the otherwise general constraint that underlying vowels of verb stems are non-high.

${ }^{21}$ As mentioned above, a special rule would be needed for verbs of type 18 in order to shorten their thematic vowel in the non-aspectual stem. 
29), and also by the verbs bala 'eat', wa:la 'spend the day', and dinabat'a 'be surprised'.

(39) k'atala 'ki11' (type 22)

a. Perfective

Genera1 A-Assoc.:

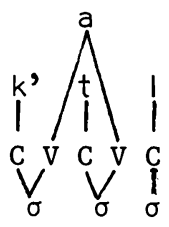

Surface: k'atal-

b. Imperfective

General A-Assoc.:

Rule (34)

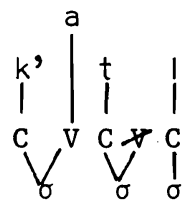

Surface: k'at 1-

c. Non-aspectual

General A-Assoc.:

Rule (35)

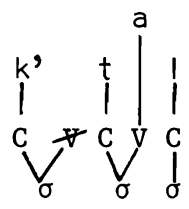

Surface: $k^{\prime}(i)$ tal-

(40) ?e:nk'afa 'embrace' (type 32)

a. Perfective

General A-Assoc.:

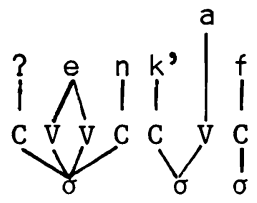

Surface: ?e:nk'af- 
b. Imperfective

General A-Assoc.: -

Rule (33)

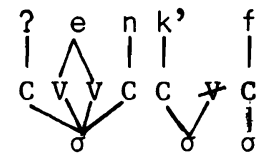

Surface: ?e:nk'(i)f-

c. Non-aspectual

General A-assoc.: -

Rule (37)

Rule (33)

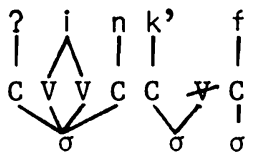

Surface: ?i:nk'(i) f-

(41) bira:Č'e 'disperse' (type 37)

(All stem forms are the same as the syllabified form shown in (29).) Surface: b(i)ra:ć-

(42) bala 'eat' (type 1)

Entry: $\mu^{\left[+V, \ldots-R_{f}\right.} \ldots$ 'eat']

Consonant tier: $b$ I

Syllabification:

Consonant tier:

Vowel tier:

CV-tier:

Syllable tier:

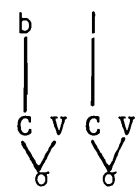

Aspectual Inflection:

a. Perfective

General A-Assoc.:

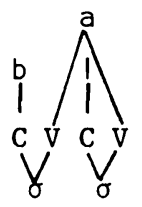

Surface: bala- 
b. Imperfective

(Same as perfective)

c. Non-aspectua1

General A-Assoc.:

Rule (35)

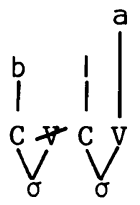

Surface: $\quad b(i) \mid a-$

(43) wa:la 'spend the day' (type 6)

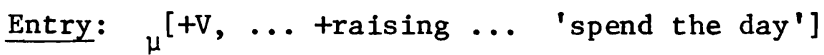

Consonant tier:

Vowe1 tier:

CV-tier:

Syllable tier:

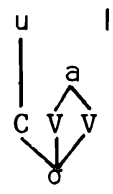

Syllabification:

Consonant tier:

Vowe1 tier:

CV-tier:

Syllable tier:

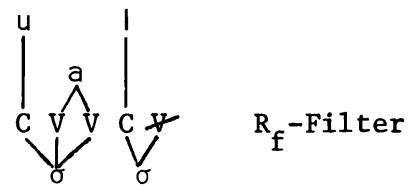

Aspectual Inflection:

a. Perfective

(Same as syllabified form)

b. Imperfective

General A-Assoc.: -

Rule (37)

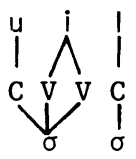

Surface: wi:l-

c. Non-aspectual

(Same as syllabified form) 
(44) dinabat'a 'be surprised' (type 38)

Entry: $\mu^{[+V}, \ldots \ldots \ldots$ 'be surprised']

Consonant tier: $d n b t$,

Syllabification:

Consonant tier:

Vowel tier:

CV-tier:

Syllable tier:

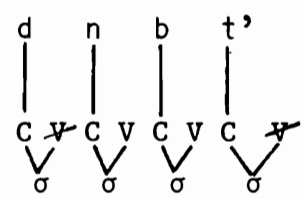

4-syll. V-Deletion; $R_{f}$-Filter

\section{Aspectual Inflection:}

a. Perfective

Genera1 A-Assoc.:

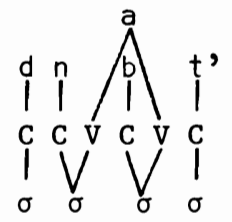

Surface: d(i) nabat'-

b. Imperfective

General A-Assoc.:

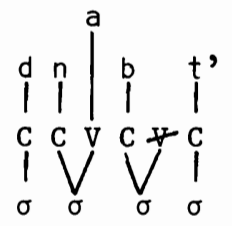

Surface: $d(i)$ nabt'-

c. Non-aspectual

General A-Assoc.: -

Rules (35) \& (36)

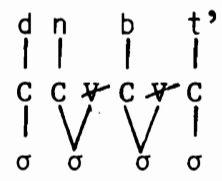

Surface: $d(i) n b(i) t^{\prime}-$ 


\section{Conclusion}

Looking back at the two goals set in the Introduction above, the following comments seem to be appropriate. While this study has attempted to reach some degree of adequacy in its description of aspectual inflection, much of what has been proposed here will no doubt need to be revised once more data are considered and the scope of the study is widened to cover such areas as derivation, inflection other than for aspect, and also phonological regularities outside the verbal system. Similarly, on the theoretical side much of what has been said here will probably turn out to be unsatisfactory as more data both from the Silt'i language and also from other languages are considered.

More important than any of these tentative specific insights seems to be the hope that this study may serve as another piece of evidence speaking for the great potential of the multi-tiered approach as an insightful linguistic theory. Given that, in line with much current research, one of the main goals here has been to attribute the complexity of relationships in a system to the interaction between a number of comparatively simple subsystems, the multitiered framework seems to be particularly well-suited to this purpose. It provides a principled way of defining and relating a variable set of subsystems, 1.e. tiers, each of which can be constrained independently of the other subsystems. 


\section{APPENDIX: Phonological Sketch}

The Silt'i language has the following phoneme inventory:

\begin{tabular}{|c|c|c|c|c|c|c|}
\hline Consonants & & Labial & Alveolar & Palatal & Velar & Glottal \\
\hline \multirow[t]{3}{*}{ Stops } & v1 & & $t(:)$ & $\check{c}(:)$ & $k(:)$ & $?$ \\
\hline & vd & $b(:)$ & $d(:)$ & $\mathrm{j}(:)$ & $g(:)$ & \\
\hline & ej & & $t^{\prime}(:)$ & $c^{\prime}(:)$ & $k^{\prime}(:)$ & \\
\hline \multirow[t]{2}{*}{ Fricatives } & $\mathrm{v} 1$ & $f(:)$ & $s(:)$ & $\int(:)$ & & $h$ \\
\hline & vd & & $z(:)$ & $\check{z}(:)$ & & \\
\hline Nasals & & $\mathrm{m}(:)$ & $\mathrm{n}(:)$ & $n(:)$ & & \\
\hline \multirow[t]{2}{*}{ Liquids } & lat. & & $I(:)$ & & & \\
\hline & centr. & & $r(:)$ & & & \\
\hline Semivowels & & $w(:)$ & & $y(:)$ & & \\
\hline \multirow[t]{4}{*}{ Vowels } & & Front & Central & Back & & \\
\hline & High & $i(:)$ & & $u(:)$ & & \\
\hline & Mid & $e(:)$ & & $O(:)$ & & \\
\hline & Low & & $a(:)$ & & & \\
\hline
\end{tabular}

In this table the following abbreviations are used: $v 1=$ voiceless, $\mathrm{vd}=$ voiced, ef = ejective, 1at. = 1ateral, centr. = central. The parenthesis (:) indicates that there is a short and a long phoneme of this sound; thus, the length of segments is contrastive. The labels are not used phonetically, but to distinguish phonological categories. For typographical reasons, my transcription differs from the IPA symbols in the following ways:

$\begin{array}{cc}\text { EAG } & \text { IPA } \\ z & t \int \\ j & d z \\ z, & t \int \\ z & 3 \\ y & j\end{array}$




\section{REFERENCES}

Anderson, S. R. 1981. "Why phonology isn't natural." Linguistic Inquiry 12: 493-539.

Bender, M. L. and Hailu Fulass. 1978. Amharic Verb Morphology. Language and Linguistics, No. 1, Monograph no. 7. East Lansing, MI: African Studies Center, Michigan State University.

Chomsky, N. and M. Halle. 1968. The Sound Pattern of English. New York: Harper and Row.

Clements, G. N. and K. C. Ford. 1979. "Kikuyu tone shift and its synchronic consequences." Linguistic Inquiry 10:179-210.

Clements, G. N. and S. J. Keyser. 1981. "A three-tiered theory of the sy11able." MIT Center for Cognitive Science Occasional Papers, 19. Cambridge, Mass.

Drewes, A. J. 1960. "Le type verbal k'ātala en gurage oriental." Bibliotheca Orientalis $17(1 / 2): 5-10$.

Goldsmith, J. A. 1979. "Autosegmental Phonology." Bloomington: Indiana University Linguistics Club.

Gutt, E.-A. 1983. "Studies in the phonology of Silt'i." Journal of Ethiopian Studies 16:37-73.

Halle, M. and J.-R. Vergnaud. 1980. "Three-dimensional phonology." Journal of Linguistic Research 1:83-105.

Hetzron, R. 1969. "Two notes on Semitic laryngeals in East Gurage." Phoneti ca 19:69-81.

Hetzron, R. 1972. Ethiopian Semitic: Studies in Classification. Journal of Semitic Studies, Monograph no 2. Manchester: Manchester University Press.

Leslau, W. 1959. "Sidamo features in the South Ethiopic phonology." Journal of the American Oriental Society 79:1-9.

Leslau, W. 1961. "Remarks on the gemination of the Gurage dialect of Azarnat Mugo." Bibliotheca Orientalis 18(1/2):19-20.

Leslau, W. 1979. Etymological Dictionary of Gurage (Ethiopic), 3 volumes. Wiesbaden: Harrassowitz.

McCarthy, J. 1981. "A prosodic theory of nonconcatenative morphology." Linguistic Inquiry 12:373-418.

McCarthy, J. 1982a. "Formal problems in Semitic phonology and morphology." Bloomington: Indiana University Linguistics Club.

McCarthy, J. 1982b. "Non-linear phonology: an overview." GLOW Newsletter, no. 8, pp. 63-77. 